\title{
Package leaflets for medication in the EU: The possibility of integrating patients' perspectives in a regulated genre?
}

\author{
Antoinette Fage-Butler \\ Department of Business Communication, Aarhus \\ University, Denmark
}

\begin{abstract}
Package leaflets (PLs) have been legally required to accompany medicines in the EU since 1999. Despite the best intentions and efforts, however, they are generally not well-received by the public for whom they are intended. This paper picks up on the challenges that medical regulatory writers face in producing quality PLs using the official PL template when research indicates that patients would prefer a more personalised genre that incorporated their experiences and knowledge. This paper advocates greater inclusion of patients' perspectives, as this is currently achievable given the current legislation. The paper also notes the tantalising prospect of replacing the template with a set of recommendations that draws on knowledge of what works best for patients.
\end{abstract}

Keywords: Package leaflets, Regulatory writers, Template, Patients' perspectives, Semi-expert patients

\section{Introduction}

This paper addresses the question: how can medical writers, for whom best practice involves writing for the reader in a 'clear, accurate, and engaging' way, ${ }^{1}$ accomplish this in a constrained, regulated genre such as the package leaflet (PL) which accompanies medications in the EU? The paper derives from my $\mathrm{PhD}$ dissertation, ${ }^{2}$ which used discourse analysis to demonstrate how attention to patients' needs is possible in PLs; the primary focus of the present paper is on practical implications for medical writing professionals.
Correspondence to:

Antoinette Fage-Butler Department of Business Communication, Aarhus University, Jens Chr. Skous Vej 4, Building 1481, Room 633, 8000 Aarhus C, Denmark fage-butler@bcom.au.dk

\section{The dilemma: Between a rock (of regulation) and a hard place (of patients' expectations)}

Since 1999, all medicines available to patients in the EU have been legally required to be accompanied by PLs, which provide information on medicines and how to use them. Although these texts are important for patients' health and safety, many patients do not value them. This is due to a number of factors, but the one that will be addressed here is patients' belief that PLs are not written with them in mind. ${ }^{3}$ They deem PLs instead to be written for professional purposes, such as meeting legal requirements and avoiding litigation, ${ }^{4}$ and consider their own perspectives and knowledge to be absent from these texts. ${ }^{5}$

Whilst genres are normally in a state of flux, ${ }^{6}$ the $\mathrm{PL}$ is a particularly constrained genre and the scope that medical writers have for improving it is impacted in a number of ways. Firstly, the PL's status as a legal, regulated genre means that a conservative approach to genre development is most likely, as any delays to approving PLs due to alternative, unapproved wordings, for example, could delay the release of products and be expensive for pharmaceutical companies. Secondly, since 1998, a template produced by the European Medicines Agency (EMA) stipulates particular content, structure, headings, and statements for PLs. The template has been revised over the years: the most recent template, dated June 2015, is called Version 9.1. Ostensibly, the template provides writers with a number of advantages. It helps to ensure that all information is present in a particular order, ensures linguistic consistency across PLs which is likely to facilitate regulatory processes, and essentially 'takes many decisions out of the hands of 
medical writers' ${ }^{8}$ However, this is also a potential disadvantage as 'templates tend to stifle innovation', 9 leading to very standardised texts. Moreover, the quality of the template has also been identified as problematic, ${ }^{8}$ with the implication that texts that are based on the template reproduce its weaknesses.

The focus of this paper is on PLs that are regulated through centralised procedures by EMA. This is worth mentioning, as PLs in the EU may be regulated either nationally or centrally at European level. In Britain, for example, PLs regulated at national level by the Medicines and Healthcare Products Regulatory Agency (MHRA) are only required to follow the set content and order specified in the legislation, ${ }^{10}$ whereas PLs that are regulated by EMA should adopt the content, order, headings, and statements of the template. If the set headings or statements of the template are not adopted by pharmaceutical companies seeking approval from EMA, each amendment is considered on a case-by-case basis and alternative headings may need to be argued for. ${ }^{7}$

\section{What kind of audience do PLs address?}

Berkenkotter ${ }^{11}$ argues that writers write with an audience in mind, and that the best writers do this to a high degree. In this way, there are implicit, if not explicitly formulated, preconceptions of an audience, traces of which are evident in the texts themselves. ${ }^{12}$ This begs the question: if patients feel that their perspective is missing, what is there then in PLs?

The answer to this question comes in part from the legal requirement that PLs, above all, be understandable. For example, Article 63(2) of Directive 2001/83/EC ${ }^{13}$ states: 'The package leaflet must be written and designed to be clear and understandable, enabling the users to act appropriately, when necessary with the help of health professionals.' Moreover, a set of readability guidelines for PLs produced by European Commission ${ }^{14}$ reminds PL producers that: 'Some people may have poor reading skills, and some may have poor health literacy. Aim to use simple words of few syllables' and 'Medical terms should be translated into language which patients can understand'. PLs, in other words, should be written with a lay audience in mind.

In a sense, this is eminently sound: as PLs provide information about medication, this information ought to be comprehensible, although Cutts, ${ }^{15}$ for example, recently illustrated that attempts to employ plain language in PLs are not always successful. Further indication that PLs are intended for a lay audience is apparent in the representation of the patient in these texts, where patients are characterised as having a health condition, as needing treatment, as possibly being forgetful and needing clarification from medical experts such as their doctor or pharmacist. All of these representations reflect the lay patient of the biomedical model of health communication. ${ }^{2}$

This assumption of patient laity may not, of course, correspond with the actual reader of the PL, as patients are increasingly using the internet to equip themselves with information. Some chronic patients, in particular, gain knowledge of their condition to such an extent that they should be considered semi-experts, even experts, on their condition. ${ }^{16}$ At the same time, however, there are also readers of PLs with low health literacy levels who need information to be expressed as simply as possible. In other words, patients exist along a broad epistemic spectrum, and although it is best practice to express information as clearly as possible, not everyone reading PLs is lay. The leaflet format as it currently stands does not make it possible to address various levels of health literacy.

At a more general level, there is lack of recognition in PLs of other aspects of patients' heterogeneity and humanity. Individual patients read PLs and find that the 'umbrella concept' of the audience does not reflect the intensely personal nature of their illness experience. ${ }^{17}$ Perhaps patients have come to expect patient-centred communication not only in the clinical setting but also in written communication. In any case, this lack of focus on the patient in PLs must be taken seriously, not only to address patients' dissatisfaction, but also because of proven educational benefits: the more targeted and individualised medical leaflets are, the more motivated patients are to read them and the better they are at recalling their content. ${ }^{18}$ The challenge for the regulatory writer is thus the following: given the template and the mass communication format of the leaflet format, how does one make PLs more personalised?

\section{On meeting regulatory demands and demands from patients}

The approach to improving PLs that is outlined in this paper is a pragmatic one. It proposes producing PLs in accordance with the template - which means that writers can more readily adopt these suggestions - whilst adding content couched in patientfriendly language that integrates patients' 
perspectives in PLs. This content-related approach is in line with Billiones, ${ }^{19}$ who, although no doubt mainly addressing a non-regulatory medical audience, urged the following: 'at the end of the day, templates do not guarantee quality documents. [...] [W]e, medical writers, are still fully responsible for the content.' Interestingly, longer PLs are not necessarily off-putting: patients have stated a general preference for longer, more detailed PLs, provided the information is relevant for them. ${ }^{3}$ Moreover, it is possible to produce better quality PLs whilst using the template. Pander Maat \& Lentz, ${ }^{20}$ for example, showed that PLs that met the template's requirements were improved (made more usable) using principles of document design.

For improvements to take place, however, there needs to be a context in which improvements can take place. The context that has impeded this genre's evolution can be addressed in two ways. The bottom-up approach involves pharmaceutical companies and regulatory writers making it a priority to include patients' perspectives to a far greater degree in the texts they produce. Such PLs would be better at engaging their publics, resulting in an increase in the safety of the medication, more ethical communication, and potentially improved customer relations. The top-down approach involves regulatory authorities such as EMA promoting more patient-oriented communication in PLs, with possible implications for changes in legislation. The integration of patients' perspectives in PLs would be an extension of EMA's growing focus on patient involvement, as is evident, for example, in EMA's use of feedback from user testing (comprehensibility tests) of existing PLs to refine the template ${ }^{7}$ and the production of a webpage for patients and carers. ${ }^{21}$ No doubt a combination of the top-down and bottom-up approaches would be the most effective for the bold changes required in this genre.

The following strategies can help support the production of PLs where patients' perspectives and knowledge are included and their needs are met:

- Gaining familiarity with patients' experiences of PLs: In order to integrate patients' perspectives in PLs, it is important to understand patients' experiences of PLs, particularly in relation to the various ways in which patients feel their perspectives are absent and their needs are not addressed. Well worth consulting in that regard, for example, is the study by Raynor et al., ${ }^{3}$ which synthesizes the findings of a comprehensive systematic literature review into the role and effectiveness of PLs with those of stakeholder workshops (including patients).

- Considering choice of health communication paradigm: When medical writers communicate with patients, they implicitly draw on health communication paradigms and their underlying assumptions. As stated earlier, the primary model of communication reflected in the current representation of the patient in PLs is the biomedical model of communication, but other models, such as patient centeredness and patient empowerment could be very relevant alternatives as they emphasise patients' perspectives, experiences and knowledge. Indeed, as shown in my $\mathrm{PhD}$ dissertation $^{2}$ which examined a dataset of 15 British PLs, three of which were regulated by EMA and 12 of which were regulated by MHRA, some aspects of patient centeredness were evident in a limited number of constructions of risk, trust and the patient (see Table 1), thus indicating that patient-centred communication, although rare, was nevertheless possible in PLs. Acquaintance with alternative health communicative frameworks or paradigms could provide the producers of PLs with inspiration regarding how to integrate aspects that reflected patients' needs, experiences and knowledge to a much greater degree.

- Knowing the patient group: In relation to meeting patients' needs, the recent paper by Lang and Esser ${ }^{22}$ in this journal on how to incorporate empathy is very valuable. The point made about using online self-help groups and patient forums to acquire better understanding of patients' perspectives is particularly useful. Patient organisations' websites for particular conditions could also provide meaningful insights into the kind of content that would make PLs more focused on particular patient groups' needs, perspectives and experiences.

Whilst these suggestions can help to integrate patients' perspectives in PLs, there are clearly challenges involved in producing effective mass communication texts for individuals. Given the tension between mass communication texts and meeting individual needs, an exciting avenue that warrants further exploration is the possibility of supplementing the PL with online alternatives (e-leaflets), which could be tailored to the individual patient and which offered patients choice regarding preferred levels of detail and specificity. 
Table 1: Aspects found in dataset of British PLs that reflect patient-centred communication

\begin{tabular}{|c|c|c|}
\hline $\begin{array}{l}\text { Discursive } \\
\text { construct }\end{array}$ & Aspects that reflect patient centeredness & Example \\
\hline risk & $\begin{array}{l}\text { The risk information is constructed as having } \\
\text { personal value and significance for the } \\
\text { individual patient }\end{array}$ & $\begin{array}{l}\text { Read all of this leaflet carefully because it contains important information } \\
\text { for you. (Canesten Dermatological Spray) }\end{array}$ \\
\hline trust & $\begin{array}{l}\text { Information is provided on the benefits of the } \\
\text { medication }\end{array}$ & $\begin{array}{l}\text { Actonel changes the bone remodeling process back to normal, returning } \\
\text { the strength to the bone structure. (Actonel) }\end{array}$ \\
\hline trust & $\begin{array}{l}\text { The patient's understanding of his/her } \\
\text { illness/condition is promoted }\end{array}$ & $\begin{array}{l}\text { The menopause is due to lowered levels of the hormones estrogen and } \\
\text { progesterone. (Premarin) }\end{array}$ \\
\hline trust & $\begin{array}{l}\text { The patient's information-seeking on product } \\
\text { is promoted }\end{array}$ & $\begin{array}{l}\text { For UK residents only: if you have any questions or would like more } \\
\text { information, call our Canesten Advice Line on } 08457585030 \text {. Calls } \\
\text { charged at local rate. (Canesten Dermatological Spray) }\end{array}$ \\
\hline trust & $\begin{array}{l}\text { The patients' difficulties with his/her illness/ } \\
\text { condition are acknowledged }\end{array}$ & $\begin{array}{l}\text { Because smoking is an addiction you may find it difficult to give up. } \\
\text { (Boots NicAssist Fruit Fresh Gum) }\end{array}$ \\
\hline trust & $\begin{array}{l}\text { Awareness of the needs and wishes of the } \\
\text { patient is projected }\end{array}$ & You can take Prozac with or without food, whatever you prefer. (Prozac) \\
\hline trust & $\begin{array}{l}\text { The medication is constructed as assisting the } \\
\text { patient }\end{array}$ & $\begin{array}{l}\text { The nicotine is sufficient to relieve the unpleasant withdrawal symptoms. } \\
\text { It will also help to stop your craving to smoke but will not give you the } \\
\text { "buzz" you get from a cigarette. (Boots NicAssist Fruit Fresh Gum) }\end{array}$ \\
\hline trust & $\begin{array}{l}\text { The patient is encouraged to deal positively } \\
\text { with any setbacks }\end{array}$ & $\begin{array}{l}\text { You might feel a sudden craving to smoke long after you have given up } \\
\text { smoking and stopped using Boots NicAssist Fruit Fresh Gum. } \\
\text { Remember you can use nicotine replacement therapy again if this } \\
\text { should happen. (Boots NicAssist Fresh Fruit Gum) }\end{array}$ \\
\hline trust & There is a commitment to the disabled & $\begin{array}{l}\text { For information in large print, tape, CD or Braille, telephone } 0800 \\
7318450 \text {. (Vermox) }\end{array}$ \\
\hline patient & $\begin{array}{l}\text { The patient is constructed as having a social } \\
\text { network }\end{array}$ & $\begin{array}{l}\text { If your husband, partner or other family members smoke too, try to get } \\
\text { them to give up with you. (Boots NicAssist Fresh Fruit Gum) }\end{array}$ \\
\hline patient & $\begin{array}{l}\text { The patient is constructed as having } \\
\text { preferences regarding his/her medication }\end{array}$ & You can take Prozac with or without food, whatever you prefer. (Prozac) \\
\hline patient & $\begin{array}{l}\text { The patient is constructed as having } \\
\text { emotions }\end{array}$ & $\begin{array}{l}\text { If you are worried about any of these things, or if you have had a stroke } \\
\text { in the past, talk to your doctor to see if you should take HRT. } \\
\text { (Premarin) }\end{array}$ \\
\hline patient & $\begin{array}{l}\text { The patient is acknowledged as experiencing } \\
\text { physical sensations }\end{array}$ & $\begin{array}{l}\text { If any painful symptoms continue after this, you should tell your doctor } \\
\text { immediately. (Chloramphenicol Eye Drops) }\end{array}$ \\
\hline patient & $\begin{array}{l}\text { The patient is constructed as potentially } \\
\text { benefitting from resources other than } \\
\text { pharmacological, such as psychological }\end{array}$ & $\begin{array}{l}\text { Prozac should be offered to a child or young person with moderate to } \\
\text { severe major depressive disorder only in combination with } \\
\text { psychological therapy. (Prozac) }\end{array}$ \\
\hline patient & $\begin{array}{l}\text { The patient is constructed as being ruled by } \\
\text { other motivations than health }\end{array}$ & $\begin{array}{l}\text { The nicotine is sufficient to relieve the unpleasant withdrawal symptoms. } \\
\text { It will also help to stop your craving to smoke but will not give you the } \\
\text { "buzz" you get from a cigarette. (Boots NicAssist Fresh Fruit Gum) }\end{array}$ \\
\hline patient & $\begin{array}{l}\text { The patient is constructed as facing potential } \\
\text { difficulties }\end{array}$ & $\begin{array}{l}\text { Because smoking is an addiction you may find it difficult to give up. } \\
\text { (Boots NicAssist Fresh Fruit Gum) }\end{array}$ \\
\hline patient & The patient is constructed as having a past & $\begin{array}{l}\text { You may have tried to stop smoking before and you know from bitter } \\
\text { experience that it's not easy to give up cigarettes. However, you have } \\
\text { now taken the first constructive step towards becoming a non- } \\
\text { smoker. (Boots NicAssist Fresh Fruit Gum) }\end{array}$ \\
\hline patient & $\begin{array}{l}\text { The patient is constructed as having a future } \\
\text { existence after the medication has been } \\
\text { taken }\end{array}$ & $\begin{array}{l}\text { After you have stopped smoking you might find that in times of stress, } \\
\text { reaching for a cigarette is the only thing that will help you through. } \\
\text { (Boots NicAssist Fresh Fruit Gum) }\end{array}$ \\
\hline patient & $\begin{array}{l}\text { The patient is constructed as needing, and } \\
\text { being influenced by, positive affirmation }\end{array}$ & Easyhaler Budesonide is easy to use. (Easyhaler Budesonide) \\
\hline patient & $\begin{array}{l}\text { The patient is constructed as needing to be } \\
\text { motivated }\end{array}$ & $\begin{array}{l}\text { However, you will find that as time goes by, your willpower becomes } \\
\text { stronger. (Boots NicAssist Fresh Fruit Gum) }\end{array}$ \\
\hline patient & $\begin{array}{l}\text { The patient is constructed as having a life } \\
\text { outside of the illness }\end{array}$ & $\begin{array}{l}\text { Do that job around the house or garden that you've been putting off, or } \\
\text { take up a hobby. (Boots NicAssist Fresh Fruit Gum) }\end{array}$ \\
\hline patient & The patient is acknowledged as an individual & $\begin{array}{l}\text { Giving up is more difficult for some people than others. If you fail to stop } \\
\text { first time, don't be disheartened. (Boots NicAssist Fresh Fruit Gum) }\end{array}$ \\
\hline
\end{tabular}

\section{Conclusion}

It is clear that PLs, as they are written for patients, ought to meet patients' needs, and that more should be done to ensure that these texts achieve that goal. The approach that has been outlined in this paper involves continued use of the template, while additional content is included to help reflect patients' perspectives and knowledge and meet patients' needs. However, given that the template has been revised many times and patients remain dissatisfied with PLs, it may be advisable in the long term to consider replacing the template with a set of recommendations that integrated the findings of research and patient feedback, and allowed regulatory writers greater freedom to respond to patients' needs. ${ }^{20,23}$

Improvements to PLs, however they take place, would help medical regulatory writers produce PLs knowing that these texts were appreciated by their recipients. Pharmaceutical companies could also benefit from more personalised PLs, as patients currently attribute poor communication in PLs to 
'big pharma's' lack of interest in their well-being. ${ }^{4}$ But the biggest beneficiaries would be patients who found that their needs were better met in PLs. This would lead to greater levels of satisfaction with these texts, as well as likely positive effects for patient empowerment, patient education, and patient health and safety.

\section{References}

1. Leventhal P. Writing matters. Medical Writing. 2012; 21(3):191-2.

2. Fage-Butler AM. Towards a new kind of patient information leaflet? Risk, trust and the value of patient centeredness [PhD]. Aarhus: Aarhus University; 2011.

3. Raynor DK, Blenkinsopp A, Knapp P, Grime J, Nicolson DJ, Pollock K, et al. A systematic review of quantitative and qualitative research on the role and effectiveness of written information available to patients about individual medicines. Health Technol Assess. 2007;11(5):i-180.

4. Björnsdóttir I, Almarsdóttir AB, Traulsen JM. The lay public's explicit and implicit definitions of drugs. Res Social Adm Pharm. 2009;5(1):40-50.

5. Raynor DK, Savage I, Knapp P, Henley J. We are the experts: people with asthma talk about their medicine information needs. Patient Educ Couns. 2004;53(2): 167-74.

6. Kain DJ. Constructing genre: A threefold typology. Tech Comm Q. 2005;14(4):375-409.

7. European Medicines Agency. Quality Review of Documents human product-information annotated template (English) version 9.1; 2015. Available from: http://www.ema.europa.eu/docs/en_GB/document_ library/Template_or_form/2009/10/WC500004368. pdf.

8. Pander Maat H, Lentz L. Using sorting data to evaluate text structure: an evidence-based proposal for restructuring patient information leaflets. Technical Communication. 2011;58(3):197-216.

9. Raynor DK. Commentary: Readability testing of patient leaflets - where to now? Scrip World Pharmaceutical News. 2008;3328:7.

10. Medicines and Healthcare Products Regulatory Agency. Best practice guidance on patient information leaflets; 2012. Available from: https://www.gov.uk/ government/uploads/system/uploads/attachment_ data/file/328405/Best_practice_guidance_on_patient_ information_leaflets.pdf.

11. Berkenkotter C. Understanding a writer's awareness of audience. Coll Compos Commun. 1981;32(4): 388-99.

12. Foucault M. The archaeology of knowledge. New York: Pantheon; 1972.

13. European Commission. Directive 2001/83/EC of the European Parliament and of the Council. Brussels: The European Parliament and the Council of the European Union; 2001.

14. European Commission. Guideline on the readability of the labelling and package leaflet of medicinal products for human use, Revision 1, 12 January 2009 Brussels: European Commission; 2009. Available from: http://ec.europa.eu/health/files/eudralex/vol2/c/2009_01_12_readability_guideline_final_en.pdf.

15. Cutts M. Making leaflets clearer for patients. Medical Writing. 2015;24(1):14-9.

16. Ferguson T. E-patients: How they can help us heal health care. White paper. E-patients Scholars Working Group, San Francisco, CA; 2007. p. 126. Available from: http://e-patients.net/e-Patients_ White_Paper.pdf.

17. Morse JM. Towards a praxis theory of suffering. Adv Nurs Sci. 2001;24(1):47-59.

18. Berry DC, Michas IC, Bersellini E. Communicating information about medication: the benefits of making it personal. Psychol Health. 2003;18(1): 127-39.

19. Billiones R. Document templates for medical writers. Medical Writing. 2014;23(1):17-21.

20. Pander Maat $H$, Lentz L. Improving the usability of patient information leaflets. Patient Educ Couns. 2010;80(1):113-9.

21. European Medicines Agency. Patients and carers; 2015. Available from: http://www.ema.europa.eu/ ema/index.jsp?curl=pages / audience/alp_audience type_000001.jsp\&mid=.

22. Lang S, Esser M. Improving patient communication by writing with empathy. Medical Writing. 2012; 21(4):305-7.

23. van der Waarde K. Measuring the quality of information in medical package leaflets: harmful or helpful? Information Desion Journal. 2008;16(3): 216-28

\section{Author information}

Antoinette Fage-Butler gained her $\mathrm{PhD}$ at the Department of Business Communication, Aarhus University Denmark, where she is currently an associate professor. Her primary research interests are within written health communication (offline and online; mass communication and one-to-one), ethical aspects of health communication, and poststructuralist approaches to discourse and genre. 